Western University

Scholarship@Western

$1-1-2018$

\title{
Interrelationships of Functional Status and Health Conditions in Children With Cerebral Palsy: A Descriptive Study.
}

Doreen Bartlett

Emily Dyszuk

Barbara Galuppi

Jan Willem Gorter

Follow this and additional works at: https://ir.lib.uwo.ca/ptpub

Part of the Physical Therapy Commons

Citation of this paper:

Bartlett, Doreen; Dyszuk, Emily; Galuppi, Barbara; and Gorter, Jan Willem, "Interrelationships of Functional Status and Health Conditions in Children With Cerebral Palsy: A Descriptive Study." (2018). Physical Therapy Publications. 58.

https://ir.lib.uwo.ca/ptpub/58 


\section{Pediatric Physical Therapy \\ Inter-relationships of functional status and health conditions in children with cerebral palsy: A descriptive study \\ --Manuscript Draft--}

\begin{tabular}{|c|c|}
\hline Manuscript Number: & PED-PT-D-17-00111R1 \\
\hline Corresponding Author: & $\begin{array}{l}\text { Doreen J Bartlett, PT, PhD } \\
\text { The University of Western Ontario } \\
\text { London, Ontario CANADA }\end{array}$ \\
\hline \multicolumn{2}{|l|}{$\begin{array}{l}\text { Corresponding Author Secondary } \\
\text { Information: }\end{array}$} \\
\hline Corresponding Author's Institution: & The University of Western Ontario \\
\hline \multicolumn{2}{|l|}{$\begin{array}{l}\text { Corresponding Author's Secondary } \\
\text { Institution: }\end{array}$} \\
\hline \multirow[t]{4}{*}{ Order of Authors: } & Doreen J Bartlett, PT, PhD \\
\hline & Emily Dyszuk, MSc \\
\hline & Barbara Galuppi, BA \\
\hline & Jan Willem Gorter, MD, PhD \\
\hline \multicolumn{2}{|c|}{ Order of Authors Secondary Information: } \\
\hline Abstract: & $\begin{array}{l}\text { Purpose: To examine the relationship among the Gross Motor Function, Manual } \\
\text { Ability, and Communication Function Classification Systems in children with cerebral } \\
\text { palsy and to determine the number and impact of health conditions in selected profiles } \\
\text { Methods: } 671 \text { children with CP aged } 2 \text { to } 12 \text { years ( } 376 \text { males; } 56 \% \text { ) were recruited } \\
\text { from sites in Canada and the US using convenience sampling. Analyses included } \\
\text { cross tabulation and averages for the number and impact of health conditions and } \\
\text { comparisons among groups. } \\
\text { Results: } 78 \text { ( } 62 \% \text { ) out of } 125 \text { possible classification combinations were recorded. The } \\
\text { most frequent were III; I II I; and II II I. With lower levels of function, the number and } \\
\text { impact of associated health conditions generally increased. } \\
\text { Conclusions: The use of functional profiles across classification systems, in } \\
\text { combination with data on the associated health conditions, provides a comprehensive } \\
\text { picture of CP for use in clinical decision making. }\end{array}$ \\
\hline
\end{tabular}




\section{Response to Reviewers}

We thank the reviewers for their subsequent review. Reviewer one had no additional comments. We have attended to Reviewer 2's comments. Changes are indicated in bold font. In this file, reviewers' comments are in regular font and our responses are italicized. Also, in this second resubmission, masking has been removed.

Reviewer \#2: Thank you for reworking this article and resubmitting. It is much improved and a valuable addition to the literature about cerebral palsy. I feel that the inclusion of the two lower functioning groups, (IV, IV, IV) and (V, V, V), improves the generalizability and usefulness of the findings.

The Introduction and Methods sections look good.

Thank you.

Results

Page 5, line 44. The information describing the results of the Tukey's post-hoc testing is hard to follow in the text. Is it possible to put it in a Table? If not, I suggest rewriting the first part of that sentence, "Tukey's post-hoc testing revealed significant difference between $(\mathrm{I}, \mathrm{I}, \mathrm{I})$ and $(\mathrm{II}, \mathrm{II}, \mathrm{I})(\mathrm{p}=0.0008) ;(\mathrm{I}, \mathrm{I}, \mathrm{I})$ and both (IV, IV, IV) and (V, V, V) . . I I know it is repetitive to put group $(I, I, I)$ in an extra time but it seems more clear.

Change made as suggested.

\section{Discussion}

The first two paragraphs only discuss the three higher functioning groups. It is confusing that all 5 groups are not included. You would still be able to make the point that CP is a heterogeneous condition and it would be more consistent with the rest of the article.

Consider combining the first and second paragraphs of the Discussion as they are both talking about the variability of $\mathrm{CP}$.

The first two paragraphs, which highlight the comparability of our results with those of Hidecker's group have been combined. Because we are relating our results to the available literature, only the most common combinations are described.

Page 7, line 38. Consider starting a new paragraph with "Additional efforts to group children with CP..." The topic seems to change here to focus on other types of testing that are used to develop these other five profiles of children with CP. Are these additional efforts and five profiles referring to another study (reference 19?), or to this study? Please clarify.

A new paragraph has been inserted. Reference 19 has been moved forward and wording changed to indicate that this was another study. 
Page 8, line 21. Consider modifying the sentence: "Children with either all level IVs or all level Vs had a greater likelihood of problems with learning, speaking, the mouth, digesting, sleeping and epilepsy..." to improve readability.

This has been revised to read "Children in classifications (IV, IV, IV) or (V, V, V) had a greater likelihood.."

Page 8, lines 29-31. The sentence compares children with good motor abilities to fragile children, which is comparing function to health status. I recommend you compare "children with good motor abilities to children with limited motor function" so it is a clear comparison.

This sentence now reads: "virtually all children with $\mathbf{C P}$ with good motor abilities survive into adulthood while the risk of death is highest in children with limited motor function. ${ }^{21 "}$

Page 9, line 19. I believe this sentence should be written with singular rather than plural so it will agree with the sentence that comes after: "Controlling emotion and behaviour has been recognized as an unmet health need..."

This change has been made and highlighted.

Page 10, lines 9-11. The sentence beginning, "The similar development and administration..." is not needed in this paragraph.

This sentence has been deleted.

Thank you for addressing the limitation of using the Child Health Conditions Questionnaire with children who are older than the reliability and validity sample. Please explain why you think using it with older children will not change the psychometric properties, especially when you have already reported that your older sample has more health conditions than the younger sample.

We have revised the final sentence in this paragraph to read: "We do not know if the psychometric properties would differ significantly when parents use it with their school-aged children." 
Inter-relationships of functional status and health conditions in children with cerebral palsy:

A descriptive study

Doreen Bartlett, Professor Emerita, School of Physical Therapy, Western University, London, ON Emily Dyszuk, Orthotic Resident, Sudbury Prosthetic and Orthotic Design, Sudbury, ON Barbara Galuppi, Project Coordinator, CanChild Centre for Childhood Disability Research, McMaster University, Hamilton, ON Jan Willem Gorter, Professor, Department of Pediatrics and Director of CanChild, McMaster University, Hamilton, ON

Short Title: Inter-relationships of Functional Status Corresponding author: Doreen Bartlett, 1588 Elborn College, Western University, London, ON N6G 1H1 Fax: (519) 661-3866_email: djbartle@uwo.ca

Conflicts of interest and sources of funding: This research was funded by the Canadian Institutes of Health Research (CIHR) Operating Grant (MOP \#119276, 2012-2017) and a Patient-Centred Outcomes Research Award (PCORI) (\#5321, 2013-2016). Emily Dyszuk was supported through a Research Assistant position from the ClHR grant. Barbara Galuppi received salary support through both grants. Jan Willem Gorter received consultant support through the PCORI award. Jan Willem Gorter holds the Scotiabank Chair in Child Health Research.. The funders have had no involvement in the study design, data collection, data analysis, manuscript preparation, and/or publication decisions. All statements in this report, including its findings and conclusions, are solely those of the authors and do not necessarily represent the views of the Patient-Centred Outcomes Research Institute (PCORI), its Board of Governors or Methodology Committee. 
Acknowledgements: We thank additional members of the On Track team Sarah Westcott McCoy, Lisa

Chiarello., Robert Palisano, Lynn Jefferies, Allyssa LaForme-Fiss, and Steve Hanna for access to the data from the On Track study.

Abstract Word Count: 201

Word Count: $\quad 3345 / 3500$

Figures / Tables $5 / 5$

References $34 / 30$ 
Dr. Linda Fetters,

Editor-in-Chief, Pediatric Physical Therapy

Dear Dr. Fetters,

Thank you so much for shepherding this 'orphan' manuscript through the review process! This is the second resubmission of the manuscript now numbered PED-PT-D-17-001111. We thank the reviewers for their final comments and look forward to the next stages. Please note that two of my co-authors questioned the shortened title (previously "Inter-relationships of functional status of children with cerebral palsy: A descriptive study and an extension of previous work" - alluding to Hidecker's work; shortened to "... A descriptive study and extension". I wonder if a revised title of "Inter-relationships of functional status and health conditions of children with cerebral palsy: A descriptive study" might be considered?

Sincerely,

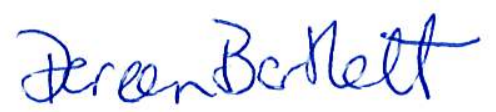

Doreen Bartlett, BSc (PT), PhD

Professor Emerita 
Abstract

Purpose: To examine the relationship among the Gross Motor Function (GMFCS), Manual Ability (MACS), and Communication Function Classification (CFCS) Systems in children with cerebral palsy (CP) and to determine the average number and impact of health conditions in selected profiles using the Child Health Conditions Questionnaire.

Methods: 671 children with CP aged 2 to 12 years (376 males; $56 \%$ ) were recruited from sites in Canada and the US using convenience sampling. Analyses included cross tabulation and averages for the number and impact of health conditions and comparisons among groups.

Results: 78 (62\%) out of 125 possible classification combinations were recorded. The most frequent were GMFCS I, MACS I, CFCS I; GMFCS I, MACS II, CFCS I; and GMFCS II, MACS II, CFCS I. Aiming for some representation across the GMFCS levels, we also explored profiles of children in levels IV and V for all three systems. With lower levels of function, the average number and average impact of associated health conditions generally increased.

Conclusions: The use of functional profiles across classification systems, in combination with data on the associated health conditions, provides a more comprehensive picture of $\mathrm{CP}$ for use in clinical decision making, than any single classification or measure alone. 
Introduction

There are two commonly used systems for classifying children with cerebral palsy (CP): systems based on anatomy or physiology versus function. Functional classification systems focus on what the child typically does instead of classifying based on impairments (such as distribution of involvement or type of movement disorder). The integration of the International Classification of Functioning, Disability and Health (ICF) framework1 into health care has helped to emphasize children's functional abilities and their typical performance in day-to-day life, rather than impairments. ${ }^{2}$ These concepts have been incorporated and used in classification systems by researchers, clinicians, and families to describe performance in mobility, handling objects, and communication. The Gross Motor Function Classification System (GMFCS), ${ }^{3}$ the Manual Ability Classification System (MACS), ${ }^{4}$ and the Communication Function Classification System $(\mathrm{CFCS})^{5}$ are three functional classification systems designed for children with CP to portray reliably their mobility habits, how they handle objects in daily life, and their communication skills with familiar and nonfamiliar partners, respectively. These classification systems can be accessed at the following sites: (https://www.canchild.ca/system/tenon/assets/attachments/000/000/058/original/GMFCS-ER_English.pdf); (http://www.macs.nu/files/MACS_English_2010.pdf); and (http://cfcs.us/wpcontent/uploads/2014/02/CFCS_universal_2012_06_06.pdf).

As there is no singular classification system for children with $\mathrm{CP}$, combining various classifications encompassing functional components of a child's life is important. ${ }^{6}$ Hidecker and colleagues described functional profiles established from the three complementary classification systems (i.e. the GMFCS, the MACS, and the CFCS). ${ }^{7}$ Although their study described a more comprehensive picture of children with CP than when classified using a single system, they did not concurrently describe impairments in body functions and associated health conditions, which are included in key components in the definition of CP. 8

It is important to ascertain the frequency and impact of impairments in body functions and associated health conditions to provide a more complete picture of the functional profiles for children with 
$\mathrm{CP}$. The primary purpose of this study was to replicate Hidecker's work ${ }^{7}$ to identify frequently occurring functional profiles for children with CP by examining the inter-relationships among the GMFCS, the MACS, and the CFCS. We hypothesized that there would be a relatively small proportion of frequently occurring profiles in children with $\mathrm{CP}$, as $\mathrm{CP}$ is a very heterogeneous condition. Secondarily, we explored the number and impact of impairments in body functions and associated health conditions in frequently occurring and additional selected functional profiles and differences among them.

Methods

This study is part of a five-year prospective cohort study: Developmental Trajectories of Impairments, Associated Health Conditions, and Participation of Children with CP (the On Track study). ${ }^{9}$ Ethical approval for this research was granted by the Health Science Research Ethics Board of Western University, as well as participating universities and sites in Canada and the United States. All ethical recommendations have been adhered to and written, informed consent for participation and publication was obtained from all legal guardians; assent was provided by children older than 7 years.

Participants

Children participating in the On Track study who had been diagnosed with CP or were suspected to have $\mathrm{CP}$ at the time of recruitment and who were between the ages of 18 months and 12 years were eligible to participate in the larger study. Ongoing eligibility was maintained throughout the study so that the final data set for analysis represented children with CP. Therapist assessors provided detailed information for consideration of eligibility of seventy-one unique cases either before or after recruitment. A physiatrist (JWG) reviewed and made recommendations to the team about any queries relating to eligibility. As a result, 11 cases were excluded. Families were excluded from the On Track study if they did not speak English, French, or Spanish. A convenience sampling approach was used to recruit participants for the study using various methods from clinical sites across Canada and the United States, including children from urban, rural, and suburban areas (see site descriptions at: https://www.canchild.ca/en/research-in- 
practice/current-studies/on-track ). Recruitment and the first data collection point took place between April 2013 and January 2015. Children in the original On Track sample of $\mathrm{N}=711$ were excluded from this substudy if they were under 24 months at the first visit $(\mathrm{N}=34)$ or if consensus information was not available for one or more of the classifications ( $\mathrm{N}=6)$. A total of 671 children were included in this descriptive sub-study. Child and caregiver respondent characteristics are described in Table 1.

\section{Measures}

The GMFCS $, 3,10$ the MACS, ${ }^{4}$ and the $\mathrm{CFCS}^{5}$ classification systems were used to determine the appropriate levels of functional ability in the areas of gross motor, manual ability, and communication for each child with CP. The three systems have a similar parallel structure and design concept, examining children's performance in everyday life by placing them into one of five levels forming an ordinal scale from level I (most functional) to level V (least functional). The three classification systems were all developed through the use of nominal group and the Delphi survey consensus methods. The GMFCS, the MACS, and the CFCS all have evidence of reliability, validity, and stability. ${ }^{3-5,50-15}$ These properties are summarized in Table 2.

The Child Health Conditions Questionnaire consists of 16 items pertaining to various impairments in body functions and health conditions of children with $\mathrm{CP} .{ }^{16}$ Items were generated based on the international definition of $\mathrm{CP}^{8}$ and most were framed based on the body functions component of the $\mathrm{ICF}^{1}$ (e.g. does your child have problems seeing, hearing, learning / understanding, speaking / communicating, and so on). Data can be reported on both number of health conditions and impact of health conditions (from $1=$ not at all to $7=$ to a very great extent) to describe the extent to which the conditions affect the child's daily activities. Test-retest reliability was established for number $(I C C=0.80)$ and the average impact $($ ICC $=0.85)$ of health conditions for children between 18 months and 5 years of age..$^{16}$ This questionnaire is available at: https://canchild.ca/system/tenon/assets/attachments/000/000/470/original/move_play_health_conditions_a 
uestionnaire_dec2012.pdf . Data obtained from the parent data collection booklets were used to describe the sample.

\section{Procedures}

Data were collected at the first data collection point of the On Track study during a one-hour assessment completed by a trained therapist and completion of a separate booklet by the parent or caregiver. Both the assessing therapist and parent or caregiver classified the child's level of involvement and consensus was reached on the level for each system. Decision algorithms and flow charts provided by all three systems ${ }^{3-5}$ were included in all study kits to aid with decisions on levels between therapists and the parent or caregiver if a consensus was not initially reached. In cases where consensus was not reached, we developed guidelines to come up with final classifications. ${ }^{17}$ All completed data collection booklets were entered into a common database for analysis.

\section{Statistical Analysis}

Inter-relationships among the GMFCS, the MACS, and the CFCS classification systems (reported in this order) were explored using nested cross tabulations, producing 125 possible combinations of functional cells. The average number and average impact of each associated health condition were calculated in selected cell combinations. Differences among the selected cell combinations was determined using a one-way ANOVA and the Kruskal-Wallis k independent samples test (and appropriate post hoc testing) for the average number and average impact of associated health conditions, respectively. Frequencies and proportions of each of the 16 health conditions was determined for the selected cells. A Chi Square test was used to determine the significant difference in proportion of health conditions among the profiles. A p value was set at 0.05 for most inferential analyses, with Bonferroni's correction being used to compare differences in the 16 health conditions among the selected groups $(p<0.003)$.

Results 
The inter-relationships among the GMFCS, the MACS, and the CFCS are displayed in Table 3 representing the functional profiles. Of the possible 125 cell combinations available, 78 combinations were present among the children in this study, representing approximately $62 \%$ of all possible combinations that could have arisen. From Table 3, the frequency of the occurrence of the same level of classification in all three systems was determined. Of the 671 children $157(23 \%)$ were found to be the same level in all three classification systems. The most common same level classification was GMFCS level I, MACS level I, and CFCS level I $(n=71,11 \%)$. Sequentially all level IIs represent 4\% ( $n=26)$, all level IIls $1 \%(n=5)$, all level IVs $4 \%(n=26)$, and all level Vs $4 \%(n=29)$

The most frequent functional profiles were considered to be those that represented $5 \%$ or more of the 671 participants and accounted for $27 \%$ of the total sample. The most frequent functional cell combinations were $(I, I, I)$ representing $11 \%(n=71)$ of the total sample, followed by $(I, I I, I)$ representing $10 \%(n=65)$, and $(I I, I I, I)$ representing $6 \%(n=37)$. To round out the exploratory portion of this sub-study, we selected two additional groups: all level IV and all level V, each representing about $4 \%$ of the sample. We selected the additional lower functioning groups as a complement to allow for greater variability in number and impact of health conditions to be described and interpreted.

The average number and average impact of associated health conditions was described for both frequent and selected (hereafter referred to as selected) functional profiles (Table 4). A significant difference in the number of associated health conditions was determined among the 5 groups $(F=81.32$, df $=4, p<0.001)$. Tukey's post-hoc testing revealed significant differences between $(I, I, I)$ and $(I I, I I, I)(p=$ 0.008); (I, I, I) and both (IV, IV, IV) and (V, V, V) (p<0.001); between (I, II I) and both (IV, IV, IV) and (V, V, V) $(p<0.001)$; between (II, II, I) and both (IV, IV, IV) and (V, V, V) $(p<0.001)$; and between (IV, IV, IV) and $(V, V, V)(p=0.001)$. Differences for average number of health conditions exceeded the minimal detectable difference at the $95 \% \mathrm{Cl}\left(\mathrm{MDC}_{95}\right)$ of 3.4 (calculated from ${ }^{16}$ ) between the three most frequent profiles and each of the two additional selected profiles. Significant differences in the average impact were determined among groups (Chi Square $=117.29, \mathrm{df}=4, \mathrm{p}<0.001$ ). Post hoc testing using the Mann 
Whitney $\mathrm{U}$ test and a Bonferroni correction of 0.01 , established differences between (I, I, I) and (II, II, I), (IV, IV, IV) and (V, V, V) (all $p<0.001)$; between (I, II, I) and (II, II, I) ( $p=0.001)$, as well as for (IV, IV, IV ) and $(\mathrm{V}, \mathrm{V}, \mathrm{V})$ (both $\mathrm{p}<0.001)$; between (II, II, I) and (IV, IV, IV) and $(\mathrm{V}, \mathrm{V}, \mathrm{V})$ (both $p<0.001)$; and finally between (IV, IV, IV) and (V, V, V) $(p<0.001)$. Again, differences for average impact of health conditions exceeded the $\mathrm{MDC}_{95}$ of 0.8 (also calculated from ${ }^{16}$ ) between the three most frequent profiles and each of the two additional selected profiles.

The number and proportion of individual associated health conditions in each of the selected functional profiles are recorded in Table 5. Using a Bonferroni correction of 0.003 , the Chi square tests show differences among the five groups for problems seeing, hearing, learning, speaking, the mouth, the teeth and gums, digestion, growth, sleeping, repeated infections, breathing and with seizures.

Discussion

Alone there is no singular classification system to describe all aspects of a child's life with CP. On their own the GMFCS, 3,10 the MACS, ${ }^{4}$ and the $\mathrm{CFCS}^{5}$ are reliable and valid classification systems that describe a child's body movement, hand function, and communication abilities in everyday life, respectively. When these three classification systems are reported together they provide a more comprehensive picture of a child with CP than with any single classification. Functional profiles of the three systems have been observed by one other study. Hidecker and colleagues ${ }^{7}$ also observed that the most common profile was children in all level I, representing $10 \%$ their total sample, a value that is similar to ours $(11 \%)$. The Hidecker group also found profile (II, II, I) to be a common profile representing $5 \%$ of the sample, which is also similar to our results (6\%). Hidecker's study was not as diverse as our study as their study filled $50 \%$ of the possible cell combinations in comparison to $62 \%$ in our study. Nonetheless, when one considers the distribution of involvement in various samples, one would not expect to see all 125 possible combinations as some are functionally unlikely. ${ }^{18}$ The fact that $73 \%$ of the sample fell into cells with fewer than $5 \%$ of the children highlights the heterogeneity of the cerebral palsy phenotype. 
Co-occurring impairments in body functions and health conditions were also reported in this study as they are included in the definition of CP. ${ }^{8}$ Overall, among the selected functional profiles, we found that as the levels increased (i.e. function decreased) in one or more of the classification systems the average number and average impact of associated health conditions also increased. A report on preschool children with $\mathrm{CP}$ found similar results regarding the number and impact of associated health conditions. Wong and colleagues reported a slightly lower frequency and average impact compared to this study, which might be explained by the younger age of the participants and the age in which associated health conditions become apparent. ${ }^{16}$

Additional efforts to group children with CP more comprehensively than with the three classification systems and health conditions alone involved using measures of spasticity, balance, distribution of involvement, strength, range of motion, endurance and impact of health conditions. ${ }^{19}$ Five 'profiles' of functioning were established using both a summative, quintile approach and cluster analysis. Although average function decreased from the most to least functional groups, similar to the observations reported in this manuscript, there was significant variability in scores on individual measures within each of the five groups, with considerable overlap between groups, a finding that has been observed by others investigating measurement scores among children at different GMFCS levels. ${ }^{20}$ We suggest that aiming for a single comprehensive classification is not useful as this over simplifies the complexity of health issues. Instead, we advocate for routine assessment with a 'suite' of measures or classification systems being interpreted separately, and in combination with each other, to understand individual children's functional and health profiles with their relative strengths and limitations, and then to plan interventions based on collaborative decisions with families (see https://www.canchild.ca/en/research-in-practice/currentstudies/on-track ).

Among the functional profiles selected for this study, children with all level V on the GMFCS, MACS and CFCS had the highest proportion of problems seeing, hearing, with teeth and gums, as well as 
with repeated infections and breathing. Children in classifications (IV, IV, IV) or (V, V, V) had a greater likelihood of problems with learning, speaking, with the mouth, with digestion and sleeping, as well as epilepsy, than children in the three more functional profiles. These results are not surprising as it is known that virtually all children with $\mathrm{CP}$ with good motor abilities survive into adulthood while the risk of death is highest in children with limited motor function. ${ }^{21}$ Nonetheless, our findings do suggest that comprehensive care coordination and additional services may be required for children CP and medical complexity to manage their many (and often impactful) associated impairments and health conditions. ${ }^{22}$ Nonetheless, even children at GMFCS level I have been observed to have a greater number of health conditions with greater impact on their lives than children without $\mathrm{CP} ; 16$ therefore, all children with $\mathrm{CP}$ could potentially benefit from having the Child Health Conditions Questionnaire completed on a routine basis, at least once a year.

Several areas of health are worth highlighting. Problems with the mouth and teeth and gums occur more frequently as functional profiles are more limited. Given that children with $\mathrm{CP}$ are at an increased risk for tooth decay, ${ }^{23}$ early oral hygiene care from appropriately trained professionals is required. Problems with digestion, growth and sleep also increase as functional profiles decrease. We agree with colleagues who have suggested that all care providers working with children with $\mathrm{CP}$ should comprehensively assess and manage physical activity, nutrition and sleep to promote health across the lifespan, suggested to be particularly important for children with lower functional abilities. ${ }^{24} \mathrm{~A}$ comprehensive review and analysis of sleep disturbances in children with $\mathrm{CP}$, including guidelines for assessment and management, is a valuable resource for front-line clinicians. ${ }^{25}$

The most commonly occurring health condition in the three most functional profiles, with no significant difference among the five selected profiles, was controlling emotions and behaviour. Controlling emotions and behaviour has been recognized as an unmet health need in children with CP compared to typically developing children..$^{26,27}$ This health condition has previously received attention as having an 
impact on children's lives. ${ }^{28-30}$ As others have found, ${ }^{31}$ the frequency and impact of pain does not differ by functional ability. Accordingly, all children with CP warrant early detection and prevention of chronic pain, where possible. Guidelines are available for assessment 32 and management (https://hollandbloorview.ca/TeachingLearning/EvidencetoCare/knowledgeproducts/PainToolbox) of pain in children with $\mathrm{CP}$.

The increase in research on $\mathrm{CP}$ over time has made it more challenging for health care practitioners to stay up to date on appropriate assessment and intervention across the spectrum of needs for children with CP. Recognition of unmet health needs can lead to changes in how health care practitioners are caring for children with $\mathrm{CP}$. Although physical therapists are not responsible for management across the range of impairments in body functions and health conditions reported here, we suggest routine use of the Child Health Conditions Questionnaire. It is psychometrically sound and readily completed with parents in five minutes. Integration of this questionnaire in examinations can lead to appropriate referral, monitoring, and care for early intervention and health promotion. ${ }^{33}$ Completion of this questionnaire with parents indicates that therapists are interested in the whole child and his or her overall health and well-being.

It is important to note that while the functional aspects of the child's life are portrayed using the three classification systems, functional aspects of associated health conditions also impact the lives of children with $\mathrm{CP}$. The additional information on the associated health conditions can help health care practitioners and families to better estimate what to expect and how to better deal and plan for these associated health conditions. Together the combination of functional profiles and associated health conditions gives a more comprehensive profile for children with $\mathrm{CP}$, than with the classification systems alone.

A limitation to the On Track study is the method in which the sample was obtained. Although not a population-based sample of children with CP, the distribution of GMFCS in this large prospective cohort 
sample of 671 participants is comparable to incidence data reported in the literature. Reid and colleagues reported mean proportions (SD) in each GMFCS level in nine international CP registries: GMFCS I - 34.2\% (13.1); GMFCS II - 25.6\% (11.6); GMFCS III - 11.5\% (2.5); GMFCS IV - 13.6\% (4.3); GMFCS V - 15.6\% (4.3). ${ }^{34}$ The proportion of children in each GMFCS level in our sample is: GMFCS I - 31.7\%; GMFCS II 23.1\%; GMFCS III - 11.3; GMFCS IV - 18.3\%; GMFCS V - 15.5\%. Another limitation to the study is that although this study determined differences among five selected functional classifications systems and the associated health conditions, there is so much more that contributes to each individual child with CP. As alluded to earlier, ${ }^{19}$ clinical practice needs to incorporate all of the heterogeneous features of children with CP. Finally, the Child Health Conditions Questionnaire has been validated for use with parents of preschool children with CP and not with parents of older children. We do not know if the psychometric properties would differ significantly when parents use it with their school-aged children. Conclusion

This study demonstrates that functional profiles can be established for children with CP by observing their GMFCS, MACS, and CFCS levels and providing a more comprehensive profile by considering impairments in body functions and associated health conditions (both number and impact on daily life). This research represents a more comprehensive picture of children with $\mathrm{CP}$, however it is important to remember that $\mathrm{CP}$ is a heterogeneous condition and more developmental domains should be taken into consideration when planning intervention to optimize outcomes within each child's prognostic potential.

References

1. World Health Organization. International Classification of Functioning, Disability and Health. Geneva: World Health Organization; 2001. 
2. Rosenbaum P, Gorter JW. The 'F-words' in childhood disability. I swear this is how we should think. Child Care Health Dev. 2012; 38:457-463.

3. Palisano R, Rosenbaum P, Bartlett D, Livingston M. Content validity of the expanded and revised Gross Motor Function Classification System. Dev Med Child Neurol. 2008; 50:744-750.

4. Eliasson A,Krumlinde-Sundholm L, Rosblad B, Beckung E, Arner M, Ohrvall A, et al. The Manual Ability Classification System (MACS) for children with cerebral palsy. Scale development and evidence of validity and reliability. Dev Med Child Neurol. 2006; 48:549-554.

5. Hidecker M, Paneth N, Rosenbaum P, Kent R, Lillie J, Eulenberg J, et al. Developing and validating the Communication Function Classification System (CFCS) for individuals with cerebral palsy. Dev Med Child Neurol. 2011; 53:704-710.

6. Rosenbaum P, Eliasson AC, Hidecker MJ, Palisano RJ. Classification in child disability: Focusing on function in the $21^{\text {st }}$ century. J Child Neurol. 2014; 29:1036-1045.

7. Hidecker M, Ho N, Dodge N, Hurvitz E, Slaughter J, Workinger M, et al. Inter-relationships of functional status in cerebral palsy: Analyzing gross motor function, manual ability, and communication function classification systems in children. Dev Med Child Neurol. 2012; 54:737-742.

8. Rosenbaum P, Paneth N, Leviton A, Goldstein M, Bax M. A report: The definition and classification of cerebral palsy. April 2006. Dev Med Child Neurol. 2007; 49(Suppl 109):8-14.

9. Westcott McCoy S, Bartlett D, Smersh M, Galuppi B, Hanna S. Monitoring development of children with cerebral palsy: the On Track Study. Protocol of a longitudinal study of development and services. Under review.

10. Palisano R, Rosenbaum P, Walter S, Wood E, Galuppi B. Development and reliability of a system to classify gross motor function in children with cerebral palsy. Dev Med Child Neurol. 1997; 39:214223. 
11. Palisano RJ, Hanna SE, Rosenbaum PL, Russell DJ, Walter SD, Wood EP, et al. Validation of a model of gross motor function for children with cerebral palsy. Phys Ther. 2000; 80:974-985.

12. Palisano RJ, Cameron D, Rosenbaum PL, Walter SD, Russell D. Stability of the Gross Motor Function Classification System. Dev Med Child Neurol. 2006; 48:424-428.

13. Öhrvall AM, Eliasson AC. Parents' and therapists' perceptions of the content of the Manual Ability Classification System, MACS. Scand J Occup Ther. 2010;17:209-216.

14. Gunel MK, Mutlu A, Tarsuslu T, Livanelioglu A. Relationship among the Manual Ability Classification System (MACS), the Gross Motor Function Classification System(GMFCS), and the function status (WeeFim) in childen with spastic cerebral palsy. Eur J Pediatri. 2009; 168:477-485.

15. Ohrvall AM, Krumlinde-Sundholm L, Eliasson AC. The stability of the Manual Ability Classification System over time. Dev Med Child Neurol. 2014; 56:185-189.

16. Wong C, Bartlett D, Chiarello L, Chang HJ, Stoskopf B. Comparison of the prevalence and impact of health problems of preschool children with and without cerebral palsy. Child Care Health Dev. 2011; 38: $128-138$.

17. Bartlett D, Galuppi B, Palisano R, Westcott McCoy S. Consensus classifications of gross motor, manual ability, and communication function classification systems between therapists and parents of children with cerebral palsy. Letter to the Editor. Dev Med Child Neurol. 2016; 58:96-99.

18. Cans C. Description of children with cerebral palsy. Steps for the future. Dev Med Child Neurol. $2012 ; 54: 679$.

19. Jeevanantham $D$, Bartlett $D$. Subgrouping children with cerebral palsy from a broader perspective using two methods. In Press Physiother Theory Pract.

20. Oeffinger D, Gorton G, Bagley A, et al. Outcome assessments in children with cerebral palsy, part 1: Descriptive characteristics of GMFCS levels I to III. Dev Med Child Neurol. 2007;49:172-180. 
21. Westbom L, Bergstrand L, Wagner P, Nordmark E. Survival at 19 years of age in a total population of children and young people with cerebral palsy. Dev Med Child Neurol. 2011;53:808-814

22. Dewan T, Cohen E. Children with medical complexity in Canada. Paediatr Child Health. 2013;18:518-522.

23. Rodrigues dos Santos B, Teresa M, Novo D, Ferrerira N, Lorenzetti S. Oral conditions in children with cerebral palsy. Am Acad Pediatr Dent. 2003; 70:40-46.

24. Verschuren $\mathrm{O}, \mathrm{McPhee} \mathrm{P}$, Rosenbaum $\mathrm{P}$, Gorter JW. The formula for health and well-being in individuals with cerebral palsy: Physical activity, sleep and nutrition. Dev Med Child Neurol. 2016;58:989-990.

25. Verschuren O, Gorter JW, Pritchard-Wiart L. Sleep: An underemphasized aspect of health and development in neurorehabilitation. Early Human Dev. In Press.

26. Goodman R, Graham P. Psychiatric problems in children with hemiplegia: Cross-sectional epidemiological survey. Br Med J. 1996;7038:1065-1069.

27. Parkes J, White-Koning M, Dickinson H, Thyen U, Arnaud C, Beckung E. Psychological problems in children with cerebral palsy: A cross sectional European study. J Child Psychol Psychiatry. 2008; 49:405-413.

28. Bjorgaas H, Elgen I, Boe T, Hysing M. Mental health in children with cerebral palsy: Does screening capture the complexity? Sci World J. 2013:468402.

29. Brossard-Racine M, Hall N, Majnemer A, Shevell M, Law M, Poulin C, et al. Behavioural problems in school-aged children with cerebral palsy. Eur J Pediatr Neurol.2012; 16:35-41.

30. McDermott S, Coker A, Mani S, Krishnaswami S, Nagel R, Barnett-Queen L, et al. A populationbased analysis of behavior problems in children with cerebral palsy. J Pediatr Psychol. 1996; 21:447-463. 
31. Doralp S, Bartlett DJ. The prevalence, distribution, and impact of pain among adolescents with cerebral palsy. Pediatr Phys Ther, 2010;22:26-33.

32. Kingsnorth S, Orava T, Provvidenza C, Adler E, Ami N, Gresley-Jones T, Mankad D, Slonim N, Fay L, Joachimides N, Hoffman A, Hung R, Fehlings D. Chronic pain assessment tools for cerebral palsy: A systematic review. Pediatrics. 2015; 136;e947.

33. Novak I. Evidence-based diagnosis, health care, and rehabilitation for children with cerebral palsy. $J$ Child Neurol. 2014; 29:1141-1156.

34. Reid SM, Carlin JB, Reddihough DS. Using the Gross Motor Function Classification System to describe patterns of motor severity in cerebral palsy. Dev Med Child Neurol. 2011; 53:1007-1012. 
Table 1. Child and Caregiver Respondent Characteristics

$\begin{array}{lc}\text { Child Characteristics } & \text { Total }(\mathrm{n}=671) \\ \text { Age - years } & \\ \text { Mean } & 6.3 \\ \text { Standard Deviation (SD) } & 2.6 \\ \text { Gender - } \mathrm{n}(\%) & \\ \text { Boy } & 376(56) \\ \text { Girl } & 295(44) \\ \text { Limb Distribution - } \mathrm{n}(\%) & \mathrm{n}=669 \\ \text { Unilateral } & 194(29) \\ \text { Monoplegia } & 5(1) \\ \text { Hemiplegia } & 189(28) \\ \text { Bilateral } & \\ \text { Diplegia } & \\ \text { Quadriplegia } & \\ \end{array}$

\section{Caregiver Respondent Characteristics}

Age - years

$(n=656)$ 


\begin{tabular}{lc}
\hline Mean & 38 \\
Standard Deviation (SD) & 7.8 \\
Relationship to child $-\mathrm{n}(\%)$ & $\mathrm{n}=665$ \\
Mother/Adoptive Mother & $585(88)$ \\
Father/Adoptive Father/Stepfather & $48(7)$ \\
Other (Aunt, Foster Mother, Grandmother, & $32(5)$ \\
Grandfather, nurse in LTC) & \\
\hline Notes: SD = Standard Deviation; LTC = Long Term Care
\end{tabular}


Table 2. Summary of the Psychometric Properties of the Classification Systems

\begin{tabular}{|c|c|c|c|}
\hline Classification System & Reliability & Validity & Stability \\
\hline GMFCS & $\begin{array}{l}\text { Inter-rater for children } \\
\text { over } 2 \text { years of age }(\mathrm{K}= \\
0.75)^{10}\end{array}$ & $\begin{array}{l}\text { Correlation with GMFM } \\
\text { scores }(r=-0.91)^{11}\end{array}$ & Yes12 \\
\hline MACS & $\begin{array}{l}\text { Inter-rater }(\mathrm{ICC}=0.97)^{4} \\
\text { Test retest }\left(\mathrm{ICC}=0.97^{4}\right.\end{array}$ & $\begin{array}{l}\text { Content validity } \\
\text { established }^{13} \\
\text { Correlation with } \\
\text { Functional } \\
\text { Independence Measure } \\
\text { for children }(r=-0.78)^{14}\end{array}$ & Yes $^{15}$ \\
\hline CFCS & $\begin{array}{l}\text { Intra-rater }(K=0.82)^{5} \\
\text { Inter-rater }(K=0.66)^{5}\end{array}$ & Content validity 5 & Not at this point \\
\hline
\end{tabular}

Notes: GMFCS = Gross Motor Function Classification System; MACS= Manual Ability Classification

System; CFCS = Communication Function Classification System, GMFM = Gross Motor Function Measure, K (Kappa co-efficient), ICC (Intraclass Correlation Co-efficient) 
Table 3: Inter-relationships of all Three Functional Classifications ( $N=671)$

\begin{tabular}{|c|c|c|c|c|c|c|c|}
\hline \multicolumn{7}{|c|}{ GMFCS level I $(n=213)$} & \multirow[t]{3}{*}{ Row totals } \\
\hline & & \multicolumn{5}{|c|}{ CFCS level } & \\
\hline & & I & $\|$ & III & IV & V & \\
\hline \multirow[t]{6}{*}{ MACS level } & I & 71 & 13 & 3 & 1 & 1 & 89 \\
\hline & $\|$ & 65 & 26 & 16 & 6 & 0 & 113 \\
\hline & III & 1 & 4 & 2 & 2 & 0 & 9 \\
\hline & IV & 0 & 0 & 1 & 1 & 0 & 2 \\
\hline & V & 0 & 0 & 0 & 0 & 0 & 0 \\
\hline & Column totals & 137 & 43 & 22 & 10 & 1 & 213 \\
\hline
\end{tabular}

GMFCS level II ( $n=155)$

Row totals

CFCS level

I II III IV V

MACS level

।

$\begin{array}{lllll}20 & 8 & 2 & 2 & 0\end{array}$

32

II

$\begin{array}{llllll}37 & 26 & 18 & 10 & 0 & 91\end{array}$

III

$\begin{array}{llllll}5 & 7 & 6 & 6 & 0 & 24\end{array}$

IV

$\begin{array}{llllll}1 & 1 & 1 & 4 & 1 & 8\end{array}$

V

$\begin{array}{lllll}0 & 0 & 0 & 0 & 0\end{array}$

0 
$\begin{array}{lllllll}\text { Column totals } & 63 & 42 & 27 & 22 & 1 & 155\end{array}$ GMFCS level III ( $n=76)$

Row totals

\section{CFCS level}

I II III IV V

MACS level

$\begin{array}{lllllll}\text { I } & 10 & 1 & 0 & 0 & 0 & 11 \\ \text { II } & 16 & 11 & 9 & 2 & 0 & 38 \\ \text { III } & 7 & 4 & 5 & 3 & 1 & 20 \\ \text { V } & 1 & 0 & 2 & 3 & 0 & 6\end{array}$

Column totals

$\begin{array}{lllll}34 & 16 & 16 & 8 & 2\end{array}$

76

GMFCS level IV ( $n=123)$

Row totals

\section{CFCS level}

MACS level

$\begin{array}{lllllll}\text { I } & 3 & 0 & 1 & 0 & 0 & 4 \\ \text { II } & 8 & 5 & 4 & 4 & 0 & 21 \\ \text { III } & 7 & 9 & 13 & 12 & 3 & 44 \\ \text { IV } & 0 & 2 & 16 & 26 & 4 & 48 \\ \text { V } & 1 & 0 & 0 & 3 & 2 & 6\end{array}$




$\begin{array}{lllllll}\text { Column totals } & 19 & 16 & 34 & 45 & 9 & 123\end{array}$

GMFCS level V $(n=104)$

Row totals

\section{CFCS level}

I II III IV V

MACS level

$\begin{array}{lllllll}\text { I } & 0 & 0 & 0 & 0 & 0 & 0 \\ \text { II II } & 0 & 0 & 1 & 1 & 0 & 2 \\ \text { IV } & 1 & 0 & 2 & 0 & 0 & 3 \\ \text { V } & 1 & 1 & 13 & 23 & 10 & 48 \\ \text { Column totals } & 3 & 1 & 23 & 38 & 39 & 104\end{array}$

"Notes: GMFCS = Gross Motor Function Classification System; MACS = Manual Ability Classification

System; CFCS = Communication Function Classification System 
Table 4: Average Number and Average Impact of Selected Associated Health Conditions

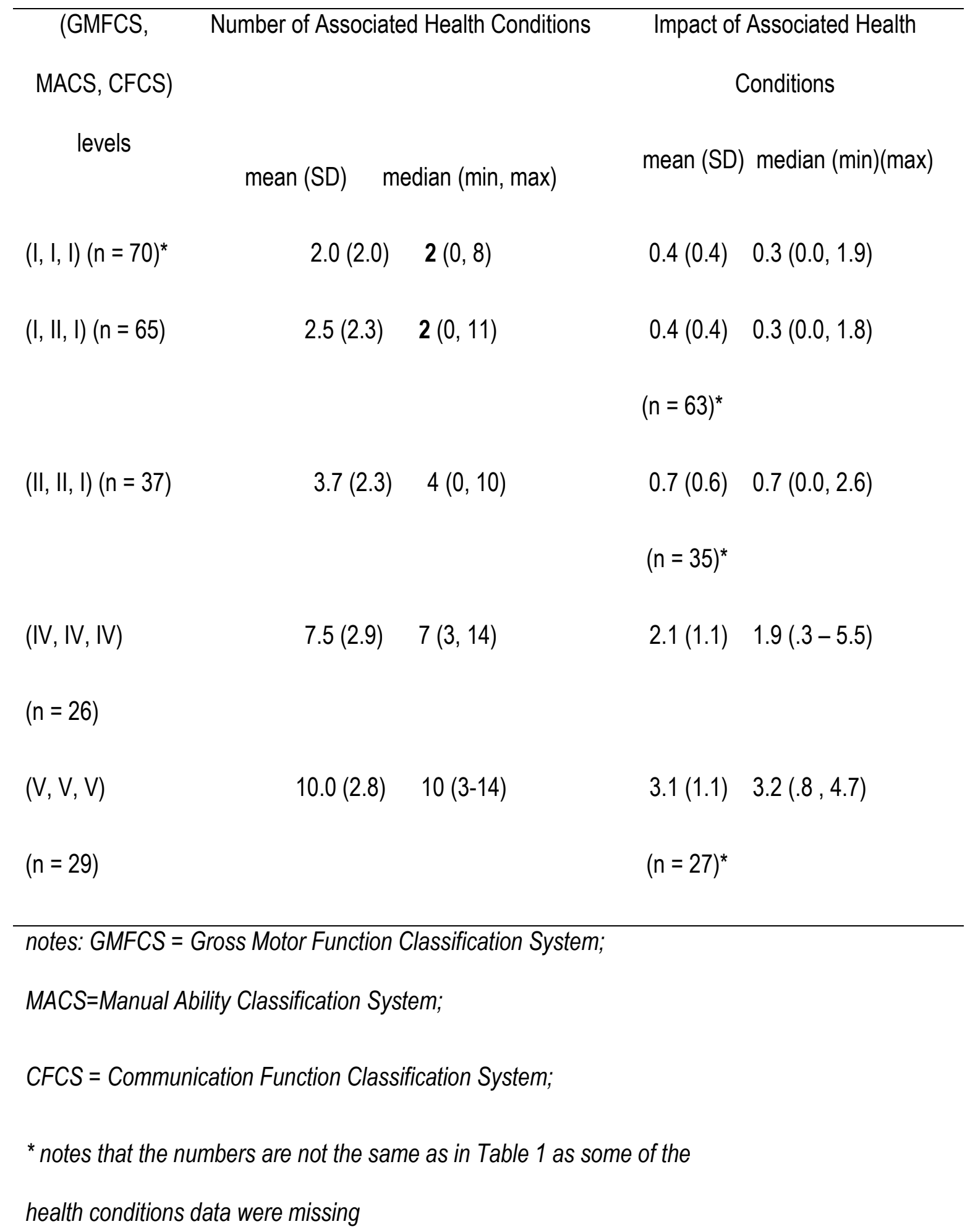


Table 5: Frequency and Proportion of Each Associated Health Condition in the Selected Groups (Bonferroni corrected $p$ value bolded if significant (i.e. $<0.003)$ )

\begin{tabular}{|c|c|c|c|c|c|c|}
\hline \multicolumn{7}{|c|}{ Health Condition $-\mathrm{n}(\%)$} \\
\hline & $(I, I, I)$ & $(I, I I, I)$ & $(I I, I I, I)$ & $(\mathrm{IV}, \mathrm{IV}, \mathrm{IV})$ & $(\mathrm{V}, \mathrm{V}, \mathrm{V})$ & $p$ value \\
\hline & $(n=70)$ & $(n=65)$ & $(n=37)$ & $(n=26)$ & $(n=29)$ & ( $\mathrm{X}^{2}$ test $)$ \\
\hline Seeing & $16(23)$ & $20(31)$ & $12(32)$ & $9(35)$ & $26(90)$ & $<0.001$ \\
\hline Hearing & $2(3)$ & $3(5)$ & $1(3)$ & $5(19)$ & $17(59)$ & $<0.001$ \\
\hline Learning/ & $15(21)$ & $21(32)$ & $11(30)$ & $22(85)$ & $28(97)$ & $<0.001$ \\
\hline \multicolumn{7}{|l|}{ understanding } \\
\hline Speaking/ & $3(4)$ & $9(14)$ & $1(3)$ & $24(92)$ & $29(100)$ & $<0.001$ \\
\hline \multicolumn{7}{|l|}{ communicating } \\
\hline \multirow[t]{2}{*}{ Emotions/behaviour } & $26(37)$ & $24(37)$ & $20(54)$ & $18(69)$ & $11(39)$ & 0.03 \\
\hline & & & & & $(n=28)$ & \\
\hline Seizures/epilepsy & $1(1)$ & $10(15)$ & $8(22)$ & $13(50)$ & $22(76)$ & $<0.001$ \\
\hline \multirow[t]{2}{*}{ Mouth } & $1(1)$ & $8(12)$ & $9(24)$ & $24(92)$ & $27(96)$ & $<0.001$ \\
\hline & & & & & $(n=28)$ & \\
\hline \multirow[t]{2}{*}{ Teeth/gums } & $0(0)$ & $3(5)$ & $4(11)$ & $6(23)$ & $14(50)$ & $<0.001$ \\
\hline & & & & & $(n=28)$ & \\
\hline
\end{tabular}




\begin{tabular}{lcccccc} 
Digestion & $1217)$ & $14(22)$ & $15(41)$ & $20(77)$ & $28(97)$ & $<.001$ \\
Growth & $7(10)$ & $7(11)$ & $7(29)$ & $11(42)$ & $15(54)$ & $<0.001$ \\
& & $(\mathrm{n}=64)$ & & & \\
& & & & & \\
Sleeping & $12(17)$ & $7(11)$ & $6(16)$ & $15(58)$ & $20(68)$ & $<.001$ \\
Repeated infections & $2(3)$ & $4(6)$ & $7(19)$ & $3(12)$ & $13(45)$ & $<0.001$ \\
Breathing problems & $9(13)$ & $6(9)$ & $12(32)$ & $7(27)$ & $17(59)$ & $<0.001$ \\
Skin problems & $15(21)$ & $11(17)$ & $5(14)$ & $6(23)$ & $6(21)$ & 0.83 \\
Heart problems & $5(7)$ & $5(8)$ & $2(5)$ & $3(12)$ & $4(14)$ & 0.73 \\
Pain & $17(24)$ & $10(15)$ & $15(41)$ & $9(35)$ & $13(45)$ & 0.01 \\
\hline
\end{tabular}


As an author of an article in Pediatric Physical Therapy I am writing to determine your eligibility for Awards given by the journal. To assist with the process please indicate below your status at the time the work reported in the article was undertaken:

I was a student at the time the work reported in the article was undertaken:

Please Check:

Yes $\mathrm{X}$

If yes, please indicate the name of the educational institution in which you were enrolled:

Educational Institution

If yes, please indicate the degree for which you were studying (i.e., MPT, DPT, MS, $\mathrm{PhD}$, etc.): 